\title{
The determination of urinary amines by one- dimensional paper chromatography
}

\author{
A. W. STOTT ${ }^{1}$ AND R. ROBINSON \\ From the Group Pathological Laboratory, Warwick
}

SYNOPSIS A method for the determination of urinary normetadrenaline and metadrenaline is described whereby these 3-O-methoxy metabolites of noradrenaline and adrenaline are separated by paper chromatography before estimation by Pisano's method. Results in 80 normal subjects are given.

The main route of metabolism of noradrenaline is by 3-O-methylation to produce normetadrenaline followed by oxidation of the normetadrenaline to give 4-hydroxy-3-methoxy mandelic acid (H.M.M.A.), also known as vanillylmandelic acid (V.M.A.). Adrenaline follows an analogous pathway, via metadrenaline to 4-hydroxy-3-methoxy mandelic acid.

There are two main reasons for measuring the excretion of normetadrenaline and metadrenaline as a reflection of the rate of secretion of noradrenaline and adrenaline respectively. First, the metadrenalines are more stable in urine, and secondly, they are about 10 times as abundant in normal urine as either noradrenaline or adrenaline.

Many workers have measured the excretion of H.M.M.A. in urine as an indication of catecholamine secretion, but this reflects only the total secretion and metabolism of noradrenaline plus adrenaline. If, however, one measures normetadrenaline and metadrenaline separately, then this gives an assessment of the individual rates of secretion of noradrenaline and adrenaline.

The following method has been evolved for the extraction, separation, and quantitative estimation of normetadrenaline and metadrenaline.

\section{REAGENTS AND EQUIPMENT}

1 Dowex cation exchange resin $\mathrm{AG}-50-\mathrm{X}_{8}$ was converted to the $\mathrm{Na}+$ form by standing overnight in $3 \mathrm{~N}$ $\mathrm{NaOH}$. After decanting the $\mathrm{NaOH}$ solution, the resin was washed with copious volumes of distilled water until the washings had a $p H$ of 7 . The resin was kept under distilled water in a dark-coloured bottle. Before use each new batch of resin should be checked for recovery. Duplicate amounts of normetadrenaline and metadrena-

${ }^{1}$ Present address: Biochemistry Department, County Hospital, York.

Received for publication 12 May 1966. line were added separately to $20 \mathrm{ml}$. portions of distilled water, which were then taken through the procedure in exactly the same way as a normal urine sample. The recoveries of the added normetadrenaline and metadrenaline were then determined. Also a new resin batch was checked against the previous batch, using duplicate samples of a 30-minute volume of normal urine whose normetadrenaline and metadrenaline values were known. This gives an added check on the degree of reproducibility of the method using different batches of resin. The recoveries of added normetadrenaline and metadrenaline from batch to batch were found to vary between 60 and $75 \%$ and values falling within this range were accepted.

$24 \mathrm{~N}$ alcoholic ammonia; $222 \mathrm{ml}$. of 0.880 ammonia solution A.R. made up to 1 litre with absolute ethyl alcohol.

$32 \%(w / v)$ sodium periodate A.R. in distilled water. $40.5 \%(\mathrm{w} / \mathrm{v})$ sodium nitrite A.R. in distilled water.

$510 \%(\mathrm{w} / \mathrm{v})$ sodium carbonate A.R. in distilled water. $60.25 \%$ p-nitroaniline solution: $1 \cdot 25 \mathrm{~g}$. of p-nitroaniline dissolved in $10 \mathrm{ml}$. of concentrated hydrochloric acid A.R. and made up to $500 \mathrm{ml}$. with distilled water.

7 Diazotized p-nitroaniline solution made freshly before use by addition $0.5 \%$ sodium nitrite dropwise to $5 \mathrm{ml}$. of p-nitroaniline solution until the latter was decolorized and then making the final volume up to $20 \mathrm{ml}$. with distilled water.

8 Standard metadrenaline solution containing $25 \mu \mathrm{g}$. metadrenaline per ml. of $0.01 \mathrm{~N} \mathrm{HCl}$.

9 Standard normetadrenaline solution containing $25 \mu \mathrm{g}$. per ml. of $0.01 \mathrm{~N} \mathrm{HCl}$.

10 Tertiary amyl alcohol A.R.

11 Chromatography tank with frame to take 10 in. square papers.

\section{METHOD}

A 24-hour urine sample is collected in a bottle containing $5 \mathrm{ml}$. of concentrated hydrochloric acid as a preservative. The volume is measured and an aliquot equal to the amount passed in $30 \mathrm{~min}$. is taken. 
The urine is brought to $p \mathrm{H} 0.9$ by dropwise addition of concentrated hydrochloric acid using a glass electrode.

The urine is then transferred to a hard glass test tube which is capped with tinfoil to prevent loss and placed in a boiling water bath for $20 \mathrm{~min}$. After cooling, the urine is filtered through a Whatman no. 1 filter paper into a small beaker and the $p \mathrm{H}$ adjusted to 7.0 by the careful addition of $40 \% \mathrm{NaOH}$, when $15 \mathrm{ml}$. of an aqueous slurry (containing approx. $3 \mathrm{~g}$.) of the cation exchange resin is added and the mixture is stirred using a magnetic stirrer for $15 \mathrm{~min}$. to allow for adsorption of the amines.

The resin is allowed to settle out and the supernatant is removed. The resin is then transferred to a $30 \mathrm{ml}$. test tube and washed by shaking successively with $10 \mathrm{ml}$. of distilled water, $5 \mathrm{ml}$. of $50 \%$ ethanol, and $20 \mathrm{ml}$. of $85 \%$ ( $v / v)$ aqueous ethanol. The tubes are centrifuged after each wash and the supernatant decanted off.

The amines are then eluted from the resin by stirring for exactly $5 \mathrm{~min}$. with $20 \mathrm{ml}$. of $4 \mathrm{~N}$. alcoholic ammonia. The eluate is filtered through a Whatman no. 1 filter paper, measured, and divided equally into two tubes. Each aliquot is now equivalent to a $15-\mathrm{min}$. sample of urine. To one is added $2.5 \mu \mathrm{g}$. of normetadrenaline and metadrenaline as marker.

The extracts are taken almost to dryness by distilling under reduced pressure at a temperature below $60^{\circ} \mathrm{C}$.; two drops of glacial acetic acid are then added to convert the amines to their more soluble acetates, and the distillation is completed. Conversion of the amines to their acetates increases their solubility and assists their transfer to paper.

For chromatography 10 in. squares of Whatman no. 1 filter papers are used. Three slots are cut out in the slow direction of the paper to provide two separate control strips 1 in. in width as shown in Figure 1.

The two central strips D,E,F,G and H,I,J,K are used, one as marker chromatogram and the other for the determination. The extracts are transferred quantitatively with methanol and deposited evenly on the squares marked

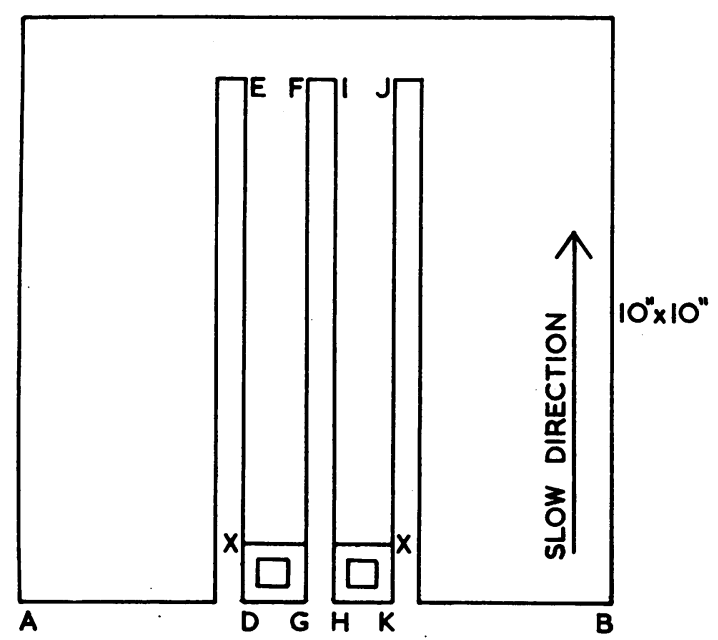

FIG. 1. Diagram showing how the filter papers are used in pencil at the bottom of the strips. The strip bearing the markers is labelled so that it can be identified subsequently.

The filter paper is then suspended in the open over a trough of methanol with the edge, $\mathrm{AB}$, just under the surface of the solvent.

The methanol is allowed to ascend to the line XX. This concentrates the amines in a narrow band along the solvent front.

The paper is dried at room temperature, placed on a frame and developed in the tank by the ascending method using tertiary amyl alcohol-0.880 ammonia (4:1) overnight.

The next morning the paper is dried in a fume cupboard at room temperature. The strip containing the markers is sprayed with $10 \%$ sodium carbonate solution, allowed to dry and sprayed with diazotized p-nitroaniline to detect the normetadrenaline and metadrenaline bands.

Diazotized p-nitroaniline was found to be the best locating reagent for the metadrenalines; it is very useful in differentiating between the closely related amine p-sympatol, which runs slightly in front of the metadrenaline band, but with which it gives a red colour as opposed to the purple colours of normetadrenaline and metadrenaline. Other sympathomimetic amines which can appear on the marker strip besides the three already mentioned are p-tyramine (purple), m-tyramine (red), 3-methoxy-tyramine (grey), and p-octopamine (red).

The approximate $\mathbf{R f}$ values of these six amines in the solvent system which was used were: normetadrenaline 0.24; metadrenaline 0.48 ; p-sympatol 0.61 ; p-tyramine $0.70 ;$ m-tyramine $0.70 ; 3$-methoxy-tyramine 0.60 ; and p-octopamine $0 \cdot 33$.

After location of the relevant normetadrenaline and metadrenaline bands, the corresponding portions of the other strip are cut out and placed in glass-stoppered centrifuge tubes containing $8 \mathrm{ml}$. of alcoholic $4 \mathrm{~N}$. ammonia. The tubes are stoppered and left for one hour to allow extraction of the amines to occur.

Each extract is then centrifuged and divided into equal portions, one to act as blank, the other for the test. To the blank is added $2.1 \mathrm{ml}$. of distilled water and to the test $2 \mathrm{ml}$. of distilled water plus $0.1 \mathrm{ml}$. of $2 \%$ sodium periodate solution. This converts the metadrenalines to vanillin (Pisano, 1960), which is then measured in a Unicam 500 S.P. at $360 \mathrm{~m} \mu$. It was found that if kept cool the vanillin formed was stable over a period of four hours.

\section{CALCULATION}

Standard amounts of normetadrenaline and metadrenaline from 0 to $20 \mu \mathrm{g}$. are converted to vanillin using the same procedure as in the test. Individual calibration curves are plotted for normetadrenaline and metadrenaline which are linear over the 0-20 $\mu \mathrm{g}$. range. The amine content of the tests is calculated from these calibration curves and the results expressed in micrograms amines per 24 hours.

\section{EXPERIMENTAL}

RECOVERY EXPERIMENTS A series of recovery experiments were carried out to determine the optimum conditions 
necessary for good and consistent recoveries. Each major stage in the method was studied to pinpoint conditions which could result in loss of amines.

Adsorption at $\mathrm{pH} 7$ for 15 minutes Standard amounts of normetadrenaline and metadrenaline were added to normal urine. A 30-min. aliquot of a 24-hr. urine specimen was then taken through the whole procedure at $p \mathrm{H} 7$ and the amount recovered determined.

All estimations were done in triplicate, using $5 \cdot 0,7 \cdot 5$, $10.0,15.0$, and $20.0 \mu \mathrm{g}$. of normetadrenaline and metadrenaline per $30-\mathrm{min}$. volume of urine.

\section{TABLE I}

RECOVERY OF STANDARDS ADDED TO URINE

\begin{tabular}{ccc}
$\begin{array}{l}\text { Amount Added }(\mu \mathrm{g} .) \\
\text { per 30-Min. Aliquot }\end{array}$ & $\begin{array}{l}\text { \% Mean Recoveries of Triplicate } \\
\text { Determinations }\end{array}$ \\
\cline { 2 - 3 } & Normetadrenaline & Metadrenaline \\
\hline $5 \cdot 0$ & 57 & 45 \\
$7 \cdot 5$ & 61 & 60 \\
$10 \cdot 0$ & 70 & 76 \\
15.0 & 50 & 58 \\
20.0 & 34 & 36
\end{tabular}

The results are shown in Table I. From the table it can be seen that recoveries reached a maximum at $10 \mu \mathrm{g}$. concentration and then fell away. Originally, $10 \mathrm{ml}$. of resin and a stirring time of only $5 \mathrm{~min}$. was tried, using a concentration of $10 \mu \mathrm{g}$. normetadrenaline and metadrenaline. This was found to result in a reduction of normetadrenaline recovery values when compared to the $15 \mathrm{ml}$. resin, $15 \mathrm{~min}$. stirring time method that was ultimately adopted (compare Table II).

Elution from resin The elution time had been arbitrarily fixed at $5 \mathrm{~min}$. It was found, however, that any increase in elution time resulted in a sharp fall in the recoveries of normetadrenaline and metadrenaline. A decrease in the elution time from 5 to $2.5 \mathrm{~min}$. also appeared to have a similar effect (Table III).
TABLE II

RECOVERY OF STANDARDS ADDED TO URINE USING ORIGINAL METHODS

\begin{tabular}{|c|c|c|c|c|}
\hline \multirow{2}{*}{$\begin{array}{l}\text { Amount } \\
\text { Added ( } \mu \mathrm{g} .) \\
\text { per } 30-\text { Minute } \\
\text { Aliquot }\end{array}$} & \multicolumn{2}{|c|}{ Percentage Recovered } & \multicolumn{2}{|c|}{$\begin{array}{l}\text { Average Percentage } \\
\text { Recovered }\end{array}$} \\
\hline & $\begin{array}{l}\text { Normet- } \\
\text { adrenaline }\end{array}$ & $\begin{array}{l}\text { Met- } \\
\text { adrenaline }\end{array}$ & $\begin{array}{l}\text { Normet- } \\
\text { adrenaline }\end{array}$ & $\begin{array}{l}\text { Met- } \\
\text { adrenaline }\end{array}$ \\
\hline $\begin{array}{l}10 \\
10 \\
10\end{array}$ & $\begin{array}{l}50 \\
60 \\
62\end{array}$ & $\begin{array}{l}78 \\
78 \\
76\end{array}$ & 57 & 77 \\
\hline
\end{tabular}

TABLE III

EFFECT OF VARYING TIME OF ELUTION FROM RESIN

Extraction Time Amount Added Percentage Mean Recoveries of (min.) ( $\mu$ g.) per Triplicate Determinations 30-Minute Aliquot

Normet- Metadrenaline

$\begin{array}{rlll}2 \cdot 5 & 10 & 53 & 43 \\ 5 \cdot 0 & 10 & 77 & 78 \\ 10 \cdot 0 & 10 & 52 & 64 \\ 15 \cdot 0 & 10 & 36 & 22\end{array}$

Extraction procedure Some early experiments were carried out with columns, but these were abandoned as the recovery of added amines was found to be very low and variable.

By adopting this technique of mechanically stirring the resin with the urine, the period in which the two were in contact was kept to the optimum for good recoveries.

Washing the resin with $85 \%$ aqueous ethanol before elution was found to produce less distorted chromatograms as the washing removes non-basic substances.

Elution from paper after chromatography Standard amounts of normetadrenaline and metadrenaline and a related amine, p-sympatol, were applied to paper chromatograms and separated by the technique described above. Recovery of the amines after extracting the paper for varying periods of time (Table IV) was found to be quite

TABLE IV

EFFECT OF VARYING TIME OF EXTRACTION FROM PAPER

\begin{tabular}{|c|c|c|c|c|c|c|c|}
\hline \multirow{2}{*}{$\begin{array}{l}\text { Extraction } \\
\text { Time } \\
\text { (hr.) }\end{array}$} & \multirow{2}{*}{$\begin{array}{l}\text { Amount } \\
\text { Added ( } \mu \mathrm{g} .) \\
\text { per 30-Minute } \\
\text { Aliquot }\end{array}$} & \multicolumn{3}{|c|}{ Percentage Recovered } & \multicolumn{3}{|c|}{ Average Percentage Recovered } \\
\hline & & Normetadrenaline & Metadrenaline & p-Sympatol & Normetadrenaline & Metadrenaline & p-Sympatol \\
\hline $0 \cdot 75$ & 10 & $\begin{array}{l}94 \\
98 \\
96\end{array}$ & $\begin{array}{l}106 \\
116 \\
114\end{array}$ & $\begin{array}{l}95 \\
88 \\
93\end{array}$ & 96 & 112 & 92 \\
\hline $1 \cdot 0$ & 10 & $\begin{array}{l}99 \\
97 \\
92\end{array}$ & $\begin{array}{l}100 \\
103 \\
121\end{array}$ & $\begin{array}{l}99 \\
98 \\
94\end{array}$ & 96 & 108 & 97 \\
\hline $1 \cdot 25$ & 10 & $\begin{array}{l}84 \\
92 \\
94\end{array}$ & $\begin{array}{l}87 \\
87 \\
96\end{array}$ & $\begin{array}{l}99 \\
95 \\
94\end{array}$ & 90 & 90 & 96 \\
\hline $2 \cdot 5$ & 10 & $\begin{array}{l}91 \\
83 \\
84\end{array}$ & $\begin{array}{r}88 \\
113 \\
93\end{array}$ & $\begin{array}{r}116 \\
96 \\
106\end{array}$ & 86 & 98 & 106 \\
\hline $4 \cdot 0$ & 10 & $\begin{array}{l}75 \\
70 \\
59\end{array}$ & $\begin{array}{l}101 \\
110 \\
107\end{array}$ & $\begin{array}{l}97 \\
94 \\
94\end{array}$ & 68 & 106 & 95 \\
\hline
\end{tabular}


TABLE V

NORMAL VALUES FOR NORMETADRENALINE AND METADRENALINE IN URINE ( $\mu \mathrm{g} . / 24 \mathrm{hr}$.)

\begin{tabular}{|c|c|c|c|c|}
\hline Authors & $\begin{array}{l}\text { No. of } \\
\text { Assays }\end{array}$ & $\begin{array}{l}\text { Mean } \\
\text { Normetadrenaline } \\
\text { Values }\end{array}$ & $\begin{array}{l}\text { Mean } \\
\text { Metadrenaline } \\
\text { Values }\end{array}$ & Total \\
\hline $\begin{array}{l}\text { Present investigation } \\
\text { Pisano (1960) } \\
\text { von Studnitz (1960) } \\
\text { Kraupp et al. (1961) } \\
\text { Smith and Weil-Malherbe (1962) } \\
\text { Yoshinaga et al. (1961) } \\
\text { Brunjes (1964) } \\
\text { Taniguchi et al. (1964) }\end{array}$ & $\begin{array}{r}80 \\
30 \\
- \\
19 \\
8 \\
47 \\
6\end{array}$ & $\begin{array}{l}239 \pm 101 \\
- \\
600 \\
160 \\
176 \\
288 \\
245 \pm 72\end{array}$ & $\begin{array}{l}253 \pm 90 \\
- \\
200 \\
80 \\
205 \\
137 \\
164 \pm 26\end{array}$ & $\begin{array}{l}492 \\
600 \pm 300 \\
800 \\
800 \\
240 \\
381 \\
425 \\
409\end{array}$ \\
\hline
\end{tabular}

high. However, in the case of normetadrenaline there was a fall in the amount recovered; after four hours' extraction time, the volume fell from $96 \%$ to $68 \%$.

The time of extraction of the amines after paper chromatography was therefore set at one hour.

It was found that after repeated duplicate estimations errors of $\pm 10 \%$ for normetadrenaline and up to $\pm 15 \%$ for metadrenaline are inevitable in the determination. The increase in the metadrenaline error compared with the normetadrenaline figure can in part be attributed to the amine p-sympatol, which can contribute to the value for metadrenaline if any is eluted from the test chromatogram.

\section{RESULTS}

The mean excretion values for normetadrenaline and metadrenaline in 80 normal subjects are shown in Table $\mathrm{V}$. The results are not corrected for percentage recovery which average overall 60 to $70 \%$.

These results are very close to the values obtained by other workers (Table V), notably Yoshinaga, Itoh, Ishida, Sato, and Wada (1961), Brünjes, Wybenga, and Johns (1964), and Taniguchi, Kakimoto, and Armstrong (1964), using highvoltage paper electrophoresis and fluorimetric techniques.

\section{DISCUSSION}

Previous workers in this field, namely, Axelrod, Senoh, and Witkop (1958), Kraupp, Bernheimer, and Papistas (1961), and Robinson and Smith (1962), used two-dimensional chromatography. Von Studnitz (1960) and Yoshinaga ét al. (1961) have used high-voltage electrophoresis followed by colorimetric determination with diazotized p-nitroaniline.

Pisano (1960) describes a method in which the total metadrenalines were measured spectrophotometrically after their oxidation to vanillin.

Smith and Weil-Malherbe (1962), Taniguchi et al. (1964), and Brunjes et al. (1964) all use fluorimetric techniques to estimate normetadrenaline and metadrenaline.

All these methods have shortcomings. Pisano's (1960) method does not differentiate between normetadrenaline and metadrenaline and is far from specific when applied to normal urine (Crout, Pisano, and Sjoerdsma, 1961).

Two-dimensional chromatography is time consuming and does not readily lend itself to precise quantitative analysis. Both high-voltage electrophoresis and fluorimetric analysis require elaborate and expensive equipment.

The method described here is perhaps not as accurate as those using high-voltage electrophoresis or fluorimetric techniques, but it is simpler and the values we obtained for normal subjects are quite close to those obtained by workers using the more specialized techniques. Our results for normetadrenaline excretion agree well, but our figures for metadrenaline are rather higher (see Table IV). This could be due to a possible tailing effect of p-sympatol which runs in front of metadrenaline and could, if eluted, absorb and give a false reading as p-hydroxybenzaldehyde at $360 \mathrm{~m} \mu$, thus contributing to the value for metadrenaline.

This method provides a relatively easy way of estimating the urinary amines, normetadrenaline, and metadrenaline and can be carried out in a normal routine laboratory using relatively unskilled personnel and normal everyday equipment.

This work was supported by a grant from the Research Sub-Committee of the Birmingham Regional Hospital Board, to whom we wish to express our thanks.

\section{REFERENCES}

Axelrod, A., Senoh, S., and Witkop, B. (1958). J. biol. Chem., 233, 697.

Brunjes, S. (1964). New Engl. J. Med., 271, 120

-, Wybenga, D., and Johns, V. J., Jr. (1964). Clin. Chem., 10, 1.

Crout, J. R., Pisano, J. J., and Sjoerdsma, A. (1961). Amer. Heart J., 61,375 .

Kakimoto, Y., and Armstrong, M. D. (1962). J. biol. Chem., 237, 208.

Kraupp, O., Bernheimer, H., and Papistas, D. (1961). Clin. chim. Acta, 6, 851.

Pisano, J. J. (1960). Ibid., 5, 406.

Robinson, R., and Smith, P. (1962). Ibid., 7, 29.

Smith, E. R. B., and Weil-Malherbe, H. (1962). J. Lab. clin. Med., 60, 212.

von Studnitz, W. (1960). Scand. J. clin. Lab. Invest., 12, suppl., 48.

Taniguchi, K., Kakimoto, Y., and Armstrong, M. D. (1964). J. Lab. clin. Med., 64, 469.

Yoshinaga, K., Itoh, C., Ishida, N., Sato, T., and Wada, Y. (1961). Nature (Lond.), 191, 599. 